\title{
Co-existence of ischemic stroke in Rheumatic and non-rheumatic atrial Fibrillation in a tertiary care teaching hospital of Western Nepal
}

\author{
Ram Chandra Kafle, Girija Shankar Jha, Navaraj Paudel, Vijay Madhav Alurkar \\ Department of Cardiology, Manipal College of Medical Sciences, Pokhara, Nepal
}

\section{Correspondence}

Dr. Ram Chandra Kafle

Department of Cardiology,

Manipal College of Medical

Sciences, Pokhara, Nepal.

Email:

drkafle30@gmail.com

DOI: http://dx.doi.org/10.3126/ jemsn.v13i4.18485

Orcid ID: orcid.org/0000-0002 $-9840-8009$

Article received: Oct $25^{\text {th }} 2017$ Article accepted: Nov $30^{\text {th }} 2017$

\begin{abstract}
Background \& Objectives: Stroke is a major public health burden worldwide leading to long-term morbidity and even mortality. Atrial fibrillation (AF) is the most common sustained arrhythmia and is an independent factor to increase risk of ischemic stroke. The risk of stroke further enhanced in rheumatic atrial fibrillation and affects younger population of developing countries. The study has aimed to find out frequency of co-existence of stroke in AF and secondarily to look for age distribution of stroke and risk factors of AF. Materials \& Methods: A retrospective analysis of trans-thoracic echocardiographic records of patients from $1^{\text {st }}$ June 2009 to $31^{\text {st }}$ June 2016 was done. Data were collected in a pre-structured proforma and analyzed. Results: Among 15767 echocardiographies, $577(3.65 \%)$ cases were recorded to have atrial fibrillation. Mean age $65( \pm 15)$ years ranging from 14 to 100 years. Rheumatic heart disease was the second most common cause of atrial fibrillation after hypertension. The co-existence of ischemic stroke was seen in $87(15.07 \%)$ cases with male to female ratio of $1: 1.3$. The proportion of stroke in rheumatic Atrial fibrillation was $21(18.75 \%)$ which was higher than in non-Rheumatic atrial fibrillation 66(14.2\%). Conclusion: Rheumatic heart disease is contributing as second most common cause of atrial fibrillation after hypertension, nearly one fourth of total stroke and most common $(93 \%)$ cause of stroke below the age of 45 years. Preventive strategies aimed at health awareness about rheumatic fever, screening programs at community level, early detection and treatment for hypertension and Rheumatic heart disease can contribute in reduction of stroke burden.
\end{abstract}

Key words: Atrial Fibrillation; risk factors; rheumatic heart disease; stroke

Citation: Kafle RC, Jha GS, Paudel N, Alurkar VM. Co-existence of ischemic stroke in Rheumatic and nonrheumatic atrial Fibrillation in a tertiary care teaching hospital of Western Nepal. JCMS Nepal. 2017;13 (4):318-22.

\section{INTRODUCTION}

Stroke is a major public health burden worldwide and is responsible for a large proportion of disability; and ranks third in causation of morbidity and mortality. ${ }^{1}$ Atrial Fibrillation (AF) is the most commonly occurring sustained arrhythmia and increases stroke risk by fivefold. ${ }^{2,3}$ In last 25 years, the incidence of AF has increased by $12.6 \%{ }^{4}$ The term Rheumatic, Idiopathic and 'lone' AF were used according to Current guidelines definitions. ${ }^{5,6}$

Though stroke is regarded as disease of older age but Stroke in young adults is in increasing trend. ${ }^{1,7}$ These strokes in young may be contributed by high prevalence of rheumatic heart disease (RHD) in developing countries like Nepal. Literature searches found that no similar study had been conducted across Nepal.

We reviewed echocardiographic records primarily to find out frequency of co-existence of stroke in $\mathrm{AF}$ and secondarily to look for age distribution of stroke and risk factors of AF.

\section{MATERIALS AND METHODS}

This retrospective descriptive analysis was conducted at Manipal teaching hospital, Pokhara, a tertiary-care hospital of western Nepal. All the 
Echocardiograms done over a period of seven years from June 2009 through June 2016 were analyzed for the present study. Permission to carry out the research and consent to review records of the patients was taken from internal review committee. Among the 16356 Echocardiograms performed during the period, only the first-time Echo of each patient with required information was included for the study to avoid repetition bias and the case records with incomplete data were excluded. Hence, a total of 15767 Echo reports were included. All echocardiograms were performed in accordance with the American College of Cardiology/American Heart Association guidelines using GE Ultrasound (Vingmed Technology, model: H45011AN) systems. ${ }^{8,9}$

Pre-completed Echocardiographic case records of patients with AF were analyzed to record relevant information including demographic data, Risk factors for $\mathrm{AF}$, cardiac valvular affection and presence or absence of ischemic stroke in a proforma. The term stroke means cardio-embolic unless otherwise specified. Continuous variables were expressed as mean $\pm \mathrm{SD}$, while categorical variables were expressed as frequency and percentages. Data was analyzed using SPSS for windows version 18.0.

\section{RESULTS}

A total of 15767 cases were underwent first time echocardiography during these seven years. Five hundred and seventy seven $(3.65 \%)$ cases between 14 to 100 years were recorded to have atrial fibrillation with mean age of $65( \pm 15)$ years. RHD was the second most common cause of atrial fibrillation after hypertension. The cases of RHD above 50 years of age were either diagnosed cases earlier and under follow up with or without valve surgery or the first time presentation of symptomatic mitral stenosis. The co-existence of ischemic stroke was seen in $87(15.07 \%)$ cases with male to female ratio of $1: 1.3$. The proportion of stroke in rheumatic AF is $21(18.75 \%)$ was higher than in non-Rheumatic AF 66(14.2\%) with $\mathrm{P}$ value of 0.22 . The rheumatic AF contributed nearly one fourth of total stroke. The stroke in rheumatic AF involved $90.5 \%$ below 60 years of age while $86.4 \%$ of non-rheumatic AF related stroke are above $60 y e a r s$. The most common risk factor for stroke in rheumatic was mitral stenosis and hypertension in non-rheumatic AF.

No gender difference was seen in AF in general while only rheumatic AF was nearly four times more commonly seen in female. The non-rheumatic $\mathrm{AF}$ was four times more common in age group of above 60 years while the rheumatic AF is five times more commonly distributed below 60 years (Table 1).

The most common risk factor associated with $\mathrm{AF}$ was hypertension (28.6\%) followed by RHD $(19.4 \%)$. No cause found in $13(2.3 \%)$ cases above 60 years were labeled as idiopathic and in 20(3.5\%) cases below 60 years were labeled as lone AF (Table 2). Diabetes mellitus was seen in $75(13 \%)$ of cases along with other risk factors. Table 3 reveals that $93 \%$ (13) of stroke below the age 45 years was caused by RHD.

\section{DISCUSSION}

The mean age of patients with AF was $65( \pm 15)$ years between 14 and 100 years which is comparable $(61.7+/-12.8)$ reported by Yoshida M et $\mathrm{al}^{10}$ from Japan. Out of 577 patients of $\mathrm{AF}$ studied, majority $(67.07 \%)$ of patients were aged between $>60$ years. There were more males $(55.30 \%)$ as compared to females. Current study shows RHD is the second most common cause of AF after hypertension which is very similar to study

Table 1: Demographic profile of patients with Rheumatic and non-rheumatic AF

\begin{tabular}{ccccc} 
Characteristics & \multicolumn{2}{c}{ Frequency(N=577) } & \multicolumn{2}{c|}{ Percentage (\%) } \\
\hline Age(years) & Rheumatic & Non-Rheumatic & Rheumatic & Non-Rheumatic \\
$<30$ & 9 & 4 & 8 & 0.9 \\
$30-45$ & 39 & 17 & 34.8 & 3.7 \\
$46-60$ & 45 & 76 & 40.2 & 16.3 \\
$>60$ & 19 & 368 & 17 & 79.1 \\
Total & 112 & 465 & 100 & 100 \\
Gender & & & & \\
Female & 89 & 208 & 79.5 & 44.7 \\
Male & 23 & 257 & 20.5 & 55.3 \\
\hline
\end{tabular}


Table 2: Risk factors associated with $\mathrm{AF}$ $(\mathbf{n}=\mathbf{5 7 7})$

$\begin{array}{lcc}\text { Risk factors } & \text { Frequency } & \mathbf{\%} \\ \text { HTN } & 165 & 28.6 \\ \text { RHD } & 112 & 19.4 \\ \text { DCM } \pm \text { Heart failure } & 41 & 7.1 \\ \begin{array}{l}\text { IHD/ ACS } \pm \text { Heart fail- } \\ \text { ure }\end{array} & 77 & 13.34 \\ \begin{array}{l}\text { Respiratory disease } \\ \text { (COPD) }\end{array} & 57 & 9.9 \\ \text { Hyperthyroidism } & 5 & 0.9 \\ \text { VHD-Degenerative } & 78 & 13.5 \\ \text { Idiopathic } & 13 & 2.3 \\ \text { Lone AF } & 20 & 3.5 \\ \begin{array}{l}\text { Others } \\ \text { (Alcohol,ASD,HCM) }\end{array} & 9 & 1.5\end{array}$

by Dhakal M. et $\mathrm{al}^{11}$ and comparable to study by Gautam et al. ${ }^{12}$ Although in western countries RHD is now very rare, it remains a major public health problem in developing countries like Nepal. It is one of the major causes of cardiovascular disease related admissions. ${ }^{13,14}$

In our study the co-existence of ischemic stroke was seen in $87(15.07 \%)$ cases which is similar $(17.65 \%)$ to study from Sikkim, India by Dhakal et $\mathrm{al}^{11}$ but lower than study from Szczecin, Poland. ${ }^{15}$ The mean age stroke patients was $65.76( \pm 16.7)$ between 25 and 94 years which is higher than figure $(61.7 \pm 14.9)$ reported by Devkota et $a^{11}$ from Kathmandu, Nepal. While the mean age of stroke only in rheumatic AF is $44.52( \pm 11.8)$ between 25 and 67 years. Unlike AF, there were more females $(56 \%)$ in stroke patients, as the majority of stroke in rheumatic AF were females. The maximum occurrence of stroke in general seen in patients $>60$ years which is in consistent with previous study from our institute. ${ }^{16}$

The proportion of stroke in rheumatic AF is 21 $(18.75 \%)$, was higher than in non-Rheumatic AF 66 (14.2\%) with $\mathrm{P}$ value of 0.22 . The Rheumatic AF contributed nearly one fourth $(24.13 \%)$ of total stroke. A systematic review of observational studies about Stroke and rheumatic heart disease by Wang $\mathrm{D}$ et $\mathrm{al}^{17}$ reported that the proportion of RHD in patients with ischemic stroke ranged from $3.4 \%$ to $23.2 \%$ in Asia and $1.8 \%$ to $2.0 \%$ in Europe and Northern America during the past 3 decades.

The most common cause of stroke in age group 14 to 45 was RHD 13(93\%) which well compares with study by Zhang YN et $\mathrm{al}^{18}$ from Southwest of
Table 3: Frequency of Ischemic stroke in rheumatic and non-rheumatic $\mathrm{AF}$

\begin{tabular}{ccc}
$\begin{array}{c}\text { Age } \\
\text { (years) }\end{array}$ & $\begin{array}{c}\text { Rheumatic } \\
\text { AF }\end{array}$ & $\begin{array}{c}\text { Stroke } \\
\text { Non-rheumatic AF }\end{array}$ \\
$<30$ & 1 & 0 \\
\hline $30-45$ & 12 & 1 \\
\hline $46-60$ & 6 & 8 \\
\hline$>60$ & 2 & 57 \\
\hline Total & 21 & 66 \\
\hline
\end{tabular}

China, the most common etiology was rheumatic heart disease (40\%). In Rheumatic AF 13(62\%) and $19(90 \%)$ of stroke affected below 45 and 60 years of age while $57(86.36 \%$ ) of stroke in non-rheumatic AF occurred after 60 years of age. These data suggest that stroke due to RHD remains a hidden burden that cannot be ignored in developing countries.

Current study, though a retrospective and hospital based, tried to cover the gap in research data in $\mathrm{AF}$ with stroke from Nepal and certainly would help to conduct prospective and community based study in the near future.

\section{CONCLUSION}

RHD is still contributing as second most common cause of AF after hypertension. Rheumatic AF contributed nearly one fourth of total stroke and most common $(93 \%)$ cause of stroke below the age of 45 years. The high $(15.07 \%)$ frequency of detection of cardioembolic stroke is either due to lack of knowledge or reluctance to start anticoagulation in indicated patients from part of treating physician or poor compliance for regular follow up for monitoring because of difficult geographical location from patient part.

Preventive strategies aimed at health awareness about rheumatic fever, screening programs at community level, early detection and treatment for hypertension and RHD can reduce stroke burden. Provision of drugs in subsidized price from government which are expensive but do not require regular monitoring can contribute in reduction of stroke related chronic morbidity and mortality.

\section{ACKNOWLEDGEMENTS:}

We are very grateful to Mrs Dibya Sharma for helping out the statistics part, also to staff in echocardiography room. 


\section{REFERENCES}

1. Devkota KC, Thapamagar SB, Malla S. Retrospective analysis of stroke and its risk factors at Nepal Medical College Teaching Hospital. Nepal Med Coll J. 2006 Dec;8 (4):269-75. PMID: 17357648.

2. Somberg JC. The impact of comorbidities on stroke prophylaxis strategies in atrial fibrillation patients. Am J Ther. 2011 Nov;18(6):510-7. https://doi.org/10.1097/ MJT.0b013e31823778db. PMID: 22072096.

3. Gołąb-Janowska M, Meller A, Kotlęga D, BajerCzajkowska A, Nowacki P. Atrial fibrillation and stroke Coexistence and attitude to preventive therapy on the basis of Szczecin and Szczecin region patients. Neurol Neurochir Pol. 2014;48(6):410-5. https://doi.org/10.1016 j.pjnns.2014.10.002

4. Medi C, Hankey GJ, Freedman SB. Stroke risk and antithrombotic strategies in atrial fibrillation. Stroke. 2010 Nov;41(11):2705-13. https://doi.org/10.1161/ STROKEAHA.110.589218. PMID: 20930160

5. Fauchier L, Philippart R, Clementy N, Bourguignon T, Angoulvant D, Ivanes F, et al. How to define valvular atrial fibrillation? Arch Cardiovasc Dis. 2015 Oct;108(10):530-9. https://doi.org/10.1016/j.acvd.2015.06.002. PMID: 26184867.

6. Potpara TS, Lip GY. Lone Atrial Fibrillation - An Overview. Int J Clin Pract. 2014;68(4):418-33. https:// doi.org/10.1111/ijcp.12281. PMID: 24372787.

7. Pokharel BR, Kharel G, Thapa LJ and Rana PVS. Stroke in Young Patients - A New Trend in Nepalese Perspective? J Nutr Disorders Ther. 2015, 5:167

8. Shrestha NR, Pilgrim T, Karki P, Bhandari R, Basnet S, Tiwari S, et al. Rheumatic Heart disease Revisited: Patterns of Valvular Involvement from a Consecutive Cohort in Eastern Nepal. J Cardiovasc Med. (Hagerstown). 2012 ;13 (11):755-59. JCM.0b013e32835854b6. PMID:22914310.

9. Cheitlin MD, Alpert JS, Armstrong WF. ACC/AHA guideline for the clinical application of echocardiography: A report of the American College of Cardiology/American Heart Association Task force on Practice guideline (Committee on clinical Application of Echocardiography). Circulation. 1997; 95: 1686-87. https:// doi.org/10.1161/01.CIR.95.6.1686. PMID: 9118558

10. Yoshida M, Nakamura Y, Higashikawa M, Kinoshita M. Predictors of ischemic stroke in non-rheumatic atrial fibrillation. Int J Cardiol. 1996 Sep;56(1):61-70. https:// doi.org/10.1016/0167-5273(96)02726-X.

11. Dhakal M, Dhakal OP, Nandy P. Epidemiology and clinical presentation of patients with atrial fibrillation from a tertiary care hospital of east sikkim: an observational study. JEMDS. 2013;20(2):3554-60. https:// doi.org/10.14260/jemds/726.

12. Gautam MP, Gautam S, Prasad SG, Subramanyam G, Ghimire U. A study of the clinical profile of atrial fibrillation in a tertiary care super-specialty referral centre in Central Nepal. Journal of College of Medical SciencesNepal. 2012;8(3):9-16. http://dx.doi.org/10.3126/ jemsn.v8i3.8679.

13. Douglas PS, Foster E, Gorscan J. ACC/AHA clinical competence statement on echocardiography. A report of the American College of Cardiology/American Heart Association/American College of Physicians/American Society of internal medicine. Task force on clinical competence ( Committee of Echocardiography) J Am Coll Cardiol. 2003; 41: 687-89. PMID: 12598084.

14. Regmi PR, Pandey MR. Rheumatic fever and RHD in school children of Kathmandu city. Indian Heart J. 1997; 49: 518-20. PMID: 9505020.

15. Gołąb-Janowska M, Meller A, Kotlęga D, BajerCzajkowska A, Nowacki P. Atrial fibrillation and stroke Coexistence and attitude to preventive therapy on the basis of Szczecin and Szczecin region patients. Neurol Neurochir
Pol. 2014;48(6):410-5.

https://doi.org/10.1016/ j.pjnns.2014.10.002.

16. Maskey A, Parajuli M, Kohli S C. A Study of Risk Factors of Stroke in Patients Admitted in Manipal Teaching Hospital, Pokhara. Kathmandu Univ Med J. 2011; 36 (4):244-7.

17. Wang D, Liu M, Lin S, Hao Z, Tao W, Chen $X$ et al. Stroke and rheumatic heart disease: a systematic review of observational studies. Clin Neurol Neurosurg. 2013 Sep;115(9):1575-82. j.clineuro.2013.06.017. PMID: 23890677.

18. Zhang YN, He L. Risk factors study of ischemic stroke in young adults in Southwest China. Sichuan Da Xue Xue Bao Yi Xue Ban. 2012 Jul;43(4):553-7. PMID: 22997895. 